\title{
Metaphors we travel by: a corpus-assisted study of metaphors in promotional tourism discourse
}

Article

Accepted Version

Jaworska, S. (2017) Metaphors we travel by: a corpus-assisted study of metaphors in promotional tourism discourse.

Metaphor and Symbol, 32 (3). pp. 161-177. ISSN 1532-7868 doi: https://doi.org/10.1080/10926488.2017.1338018 Available at https://centaur.reading.ac.uk/69755/

It is advisable to refer to the publisher's version if you intend to cite from the work. See Guidance on citing.

To link to this article DOI: http://dx.doi.org/10.1080/10926488.2017.1338018

Publisher: Taylor \& Francis

All outputs in CentAUR are protected by Intellectual Property Rights law, including copyright law. Copyright and IPR is retained by the creators or other copyright holders. Terms and conditions for use of this material are defined in the End User Agreement.

www.reading.ac.uk/centaur

\section{CentAUR}


Central Archive at the University of Reading

Reading's research outputs online 


\title{
Metaphors we travel by: a corpus-assisted study of metaphors in promotional tourism
}

\section{discourse}

Sylvia Jaworska

Dept. of English Language and Applied Linguistics

University of Reading

Whiteknights

Reading RG6 6AW, UK

Email: s.jaworska@reading.ac.uk

\begin{abstract}
Despite the widely disseminated assumption that metaphors are the key persuasive devices in promoting tourist destinations specifically those located in tropical regions, there has been to date no systematic research investigating the use of figurative language in tourism promotional discourse. Using a corpus-assisted approach to the identification and analysis of metaphors supported by Wmatrix, this study attempts to establish empirically whether promotion of destinations culturally and geographically faraway does deploy more metaphors than marketing of tourist places 'closer' to home and what kind of conceptual mappings and metaphorical expressions are utilised. The results point to a significant increase of metaphor use in the descriptions of tropical destinations. Five domains BODY, NATURAL PRECIOUS ELEMENT, COLOUR, TASTE and RELIGION prove especially productive. The combinations of metaphorical expressions from these domains generate sensory fusions that appeal to multiple senses at once including vision, taste and imagination, and in doing so, potentially increase the 'appetite' for 'consuming' a destination. They also perform ideological work as devices in discourse that clandestinely perpetuates colonial legacies.
\end{abstract}

Keywords: tourism, cultural distance, corpus-based approach, conceptual mappings, Wmatrix, colonial legacy 


\section{Introduction}

In his seminal work on the language of tourism, Dann (1996) posits an intriguing claim about the significance of geographical and cultural distance between the point of departure and tourist destinations on the ways in which tourist places are discursively constructed. $\mathrm{He}$ argues that the greater the distance is in geographical but especially cultural terms, the more metaphors and similes are employed in descriptions of tourist places. In his view, one of the main reasons for this increased use of figurative language is its ability to reduce what he calls the effect of strangeness by turning an unfamiliar phenomenon into something familiar and recognisable (Dann 1996: 173). In a later contribution, Dann (2002) again emphasises the significance of figurative language, especially in targeting destinations in the developing world. While Dann's claim is plausible, there is very little empirical evidence to substantiate it and his own contribution is based on a few examples - something which the author recognises.

Alongside the ability of transforming unfamiliar scenarios into more familiar ones, metaphors have been shown to carry an immense persuasive potential often deliberately exploited by marketers to influence people's thinking and actions. Yet, little is known about the use and functions of metaphors in the domain of tourism promotional discourse, which is inherently persuasive influencing potentially a very large number of people. Tourism is, after all, one of the major global service industries. Alone in 2014, there were over one billion tourists travelling around the globe (UNWTO Tourism Highlights, 2014). The impact of texts and images produced by the tourism industry on the perceptions and decision-making behaviours of tourists, especially purchase intentions, has been established in research (e.g. Bigné et al. 2001; Chen and Tsai 2007). Yet, the role of linguistic devices of persuasion such as metaphors in this discursive domain has to date received little attention. 
Using a corpus-assisted approach to the identification and analysis of metaphors supported by Wmatrix (Rayson 2008), this study investigates the relationship between the distance and the use of metaphors in promotional tourism discourse. More specifically, this study attempts to establish whether promotion of faraway destinations does deploy more metaphors than marketing of tourist places closer to 'home' and what kind of conceptual mappings and metaphorical expressions are primarily utilised for this purpose. In doing so, this study seeks to contribute to a better understanding of the role of metaphors in the mechanics of persuasion in promotional discourse. For the purpose of this paper, promotional discourse is defined as a type of text and talk that depict selected products and services in favourable light with the view to influence audiences for commercial benefits (Erjavec 2004).

The remaining part of the paper proceeds as follows: since this study is concerned with the use of metaphors in promotional discourse of the tourism industry, Section 2 provides an overview of linguistic research that explores the use of figurative language in promotional discourse, specifically marketing and advertising. Section 3 outlines the corpus-assisted approach adopted in this investigation and describes the data under study. Section 4 presents the main results with examples of linguistic metaphors identified in five most salient conceptual domains. Section 5 summarises the findings and discusses avenues for future research.

\section{Promotional Discourse and Metaphors}

Metaphors have long been recognised as powerful devices of persuasion (e.g. CharterisBlack 2004) and hence, it should not be surprising to find many instances of metaphorical language in promotional discourse, especially in its most central genre that of advertising (Bhatia 2005). Breeze (2013: 155) even goes so far as to claim that metaphoricity and 
analogy are the most important features of advertisement and precisely the devices that make adverts so effective and powerful. By building chains of associations between advertised products and selected positive domains, the marketers project an enhanced image of goods endowing them with desirable attributes. The richer the source domains of the employed metaphors are the more associations are created leading to stronger effects. In the world of mass consumption in which many products are very similar, metaphors are deployed to create unique associations and contribute to the creation of distinctive brands (Breeze 2013, Koller 2009). Using experimental techniques, research in marketing and business studies has demonstrated that both conventional and novel metaphors play a crucial role in influencing customers' perceptions. They largely contribute to forming favourable attitudes and purchase intentions (McQuarrie and Mick 1999; Phillips and McQuarrie 2009; Burgers et al. 2015) and are often associated with sophistication (Ang and Lim 2006).

While metaphor research in marketing provides empirical evidence for strong persuasive effects of metaphors on consumers, the studies test a selected number of metaphorical expressions and do not account for the diversity of cross-domain mappings and metaphors. This is important because different mappings can have different effects on perceptions and actions (Thibodeau and Boroditsky 2011) or different domains of promotional discourse might draw on different conceptual associations. A systematic analysis of metaphors in different genres of promotional discourse is still to be undertaken. Linguistic research makes here some contribution, albeit a modest one. Drawing on the conceptual metaphor theory (Lakoff and Johnson 1980), Abuczki (2009) analyses metaphors in adverts published in the Hungarian version of the highly popular women's fashion magazine 'Cosmopolitan' and identifies the following conceptual mappings: INTIMACY IS PHYSICAL CLOSENESS, PRODUCT IS A FRIEND, PASSION IS HEAT and SEXUAL DESIRE IS HUNGER. Caballero (2009) investigates metaphors in the genres of wine promotion in French and Spanish revealing the following 
conceptual metaphors: WINE IS A LIVING ORGANISM, WINE IS A TEXTILE and WINE IS A BUILDING. Koller (2009) and Velasco-Sacristán and Fuertes-Olivera (2005) explore the ideological potential of metaphors in promotional discourse. Studying corporate mission statements and brand artefacts, Koller (2009) shows the pervasiveness of two related conceptual mappings BRANDS ARE LIVING ORGANISMS and BRANDS ARE PEOPLE at both the verbal and visual level of corporate communication. Adopting a critical cognitive-pragmatic approach, Velasco-Sacristán and Fuertes-Olivera (2005) show how metaphors reproduce stereotypical gendered and sexist representations in adverts.

Although small in scope, linguistic research on metaphors in adverts and corporate communication has revealed a number of distinctive facets of the use of metaphors in promotional discourse. This research has also demonstrated the dual working of persuasion in metaphors. On the one hand, metaphors work overtly at the level of consciousness and help capture and comprehend abstract and sensory experiences that are otherwise difficult to express in words. On the other hand, they create a range of implicatures that transmit ideologically laden messages which deliberately emphasise certain aspects of reality and conceal others (Charteris-Black 2004).

The tourist experience with its essentially multisensory basis is a prime area for the use of metaphorical language. In fact, tourism as an object of academic inquiry has often been conceptualised in figurative terms, specifically by drawing on the source domain of BODY. Following the socio-cultural turn in tourism research, tourist places began to be explored as semiotic places that are 'consumed' by tourists. Fundamental to this consumption is the process of seeing or in Urry's (1990) term gazing. Tourism itself has been a source domain for many aspects of modern life. The flow of people and images so inherent in tourism has been seen as symptomatic of the increasingly mobile society with 'good' life being equated with a continuous holiday (Bauman 1993). The area in which metaphors play a particularly 
prominent role is the domain of promotional texts that are produced en masse by the tourism industry. Given that tourism is from the point of view of the consumer a 'risky purchase' and tourists are becoming more demanding with ever changing expectations and needs (Djafarova and Andersen 2008), the industry is constantly under pressure to use novel persuasive techniques and produce eye-catching imageries that attract customers. Since metaphors cause semantic and pragmatic tensions often in unexpected ways (novel metaphors especially) (Charteris-Black 2004), they can be effective devices of attention-grabbing. Also, in promotional discourse, where the space is limited and expensive, metaphors known as being 'pregnant with meaning' (Gibbs 2010: 11) offer a condensed way of communicating different meanings and associations at once leaving the reader to extract and interpret them against the background of their own knowledge (Djafarova and Andersen 2008).

With the claim that "phrase comes before gaze", Dann (1996: 2) was the first to draw our attention to the importance of figurative language in the promotion of tourist destinations. Alongside imperatives, buzzwords, languaging and humour, he considers metaphors and similes to be the key persuasive devices that convert tourism, which is not a basic need, into a desire and a must. Having said that, the tourism industry seems to be rather selective or strategic in the use of metaphors (e.g. Mattiello 2012). For example, Dann (1996, 2002) observes that figurative language is increasingly employed in the marketing of destinations which are further away from the point of departure, mostly tropical destinations in the developing world. This would suggest that texts promoting faraway destinations would have a greater persuasive potential and would construct tourist places as more desirable than texts marketing destinations closer to home. The evidence for this has to be yet established. Comparing the use of metaphors in promotional tourism discourse targeting different destinations could reveal whether there is an increase in the use of figurative language with a greater geographical and cultural distance and how specifically metaphors are employed to 
turn a place into a desired destination and the reader into a potential tourist/buyer.

Understanding such mechanisms of persuasion is important, because no place is inherently touristic but is constructed to be so through language, figurative language in particular (Dann 1996).

Despite the significance of metaphors in persuasive promotional discourse, there has been to-date no systematic account of metaphorical expressions in tourism. Only two studies have looked at metaphors in this domain. Djafarova and Andersen (2008) examine the frequency and types of metaphors in British tourism adverts published in the 1970s and in 2005. The authors noticed a decrease in the use of metaphorical language overall, which they attribute to the increased need for more specific and factual information. Nevertheless, metaphors are still used in tourism ads, where they seem to serve a variety of functions including attentiongrabbing and making the reader to think outside the box by inviting several interpretations and associations. The authors also see metaphors as a potential source of misinformation sometimes deliberately applied to present a place as more attractive than it really is. Although the authors did not specify what kind of destinations were advertised in the studied sample, it is interesting to note that most of the cited examples of metaphors come from the descriptions of tropical, faraway destinations. Using the framework of relevance-oriented lexical pragmatics, Mattiello (2012) examines the use of metaphors in tourist texts on the web. Her research shows that there is a diversity of metaphorical expressions used in the tourism industry ranging from conventional to very poetic metaphors. Metaphors also tend to occur together with hyperboles and in chains of metaphorical expressions, which greatly intensifies the persuasive effect.

Although the two studies offer a number of relevant insights into the functions of metaphors in tourism discourse, they are either limited to a small sample (Mattiello 2012) or do not offer a systematic account of metaphors and their conceptual mappings (Djafarova and 
Andersen 2008). Because tourism is primarily experienced and appreciated through physical and emotional sensations of, for example, movement, taste and joy, it seems especially intriguing to examine whether persuasion in this domain draws on any particular conceptual mappings grounded in physical and bodily experiences and how prevalent this use is.

This study seeks to offer more systematic insights into the use of metaphors in promotional tourism discourse. It is specifically interested to identify whether:

1) the use of figurative language in tourism promotional discourse increases with a greater geographical and cultural distance (taking Britain as the point of departure)?

2) If so, which domains are especially productive as source domains?

3) Are there any conceptual mappings typically deployed in tourism promotional discourse?

These research questions are explored by comparing the use of metaphors in three corpora that consist of commercial descriptions promoting tourist places at 'home', that is, in Britain (Home-Corpus), in Europe (Europe-Corpus) and in faraway tropical destinations (FarawayCorpus). Before discussing the results, the next section explains the procedures involved in the data collection and the corpus-assisted analysis adopted to identify and analyse linguistic metaphors and related conceptual mappings.

\section{Methodology and Data}

\subsection{Methodological and challenges}

It is generally acknowledged that identifying metaphors in discourse is a not an easy task (Semino et al. 2004). The sheer diversity of metaphors and metaphorical expressions and the fact that they are rarely tied to a specific linguistic form are challenges that the researcher is immediately confronted with (Gibbs 2010). Diachronic language change that renders some metaphors dead or highly conventionalised and thus not immediately recognisable 
compounds the issue (Deignan 2005). Moreover, the difference between literal and nonliteral meaning is, in many cases, blurred and the degree of metaphoricity varies between contexts in which a lexical item is used (Gibbs 2010).

In a linguistic analysis of metaphors in texts - something which this paper is concerned with - most researchers rely on their intuition in recognising and analysing metaphors. This inescapably results in subjective judgments and biases making it difficult to replicate or generalise from obtained results (Gibbs 2010). To overcome the problems, metaphor researchers have developed a number of criteria to assist others in the process of metaphor identification. One of the most widely adopted guidelines is the Metaphor Identification Procedure (MIP) developed by the Pragglejaz Group (2007). Although not without some shortcomings, the MIP approach has been developed to help researchers identify metaphors in naturally-occurring discourse data and hence, it will be adopted in this study too (see section 3.2).

Another important development in metaphor research has been the use of corpora and corpus methods (Gibbs 2010). As larger corpora and corpus-linguistic software programmes became widely available, many researchers began to employ corpus tools for the purpose of metaphor identification and analysis (e.g. Charteris-Black 2004; Musolff 2004; Semino et al. 2004; Deignan 2005; Koller 2006; Partington 2006). In contrast to the traditional approach, which is normally based on manual extraction of metaphors from a smaller sample of texts, corpus methods allow the researcher to examine, in a semi-automated way, metaphors in large collections of texts and reveal typical rather than idiosyncratic uses. This, in turn, can offer a more systematic and rigorous account of the distribution and prevalence of metaphors in a given discourse domain. Having said that, corpus-approaches to metaphor analysis are still constrained. Because metaphors are not tied to any specific linguistic forms, corpusbased metaphor identification is only partially automated and still involves a fair amount of 
manual analysis. A full automation is yet to be developed (Demmen et al. 2015). In the meantime, researchers using corpus tools for metaphor identification usually combine automatic quantitative corpus methods with a manual qualitative analysis (e.g. CharterisBlack 2004; Musolff 2004; Deignan 2005; Koller 2006). A sample of the corpus is either studied in depth to identify lexical items used metaphorically or a list of selected metaphorical expressions is drafted based on the knowledge of the source and target domains. A corpus is then searched for all instances of the pre-defined items and concordance lines are scrutinised to distinguish true metaphorical uses from literal ones. While this approach offers more reliable quantitative and qualitative insights, it does not capture well the diversity of metaphorical expressions that might exist in the given corpus. Ultimately, the researcher finds instances of items that she or he has identified a priori (Demmen et al. 2015).

A more promising corpus-based approach to the identification and analysis of metaphors has recently been developed by Koller et al. (2008) and Demmen et al. (2015), who utilise a corpus-linguistic web-based tool Wmatrix developed by Paul Rayson (Rayson 2008). Specifically, the UCREL semantic annotation scheme (USAS), which assigns tokens to semantic domains and is one of the components available in Wmatrix, has been proven to be a more reliable tool for the identification of a range of linguistic metaphors in selected source domains. For the purpose of this study, Wmatrix was also employed and the procedures used are largely based on the steps recommended by Demmen et al. (2015).

A related problem to which corpora and corpus tools can offer some solutions is the identification of conceptual cross-domain mappings. The notion of conceptual mappings goes back to the Conceptual Metaphor Theory (Lakoff and Johnson 1980), which influenced most of the recent linguistic analyses of metaphors in discourse. While this theory has demonstrated the ubiquity and systematicity of conceptual metaphors in general language use as well as specific discursive domains such as politics (e.g. Charteris-Black 2004; Musolff 
2004), business (e.g. Koller 2006) and health communication (e.g. Demmen et al. 2015), concerns have been raised regarding the adequate extrapolation of conceptual mappings from linguistic metaphors specifically in real-life language data (Semino et al. 2004). It has been argued that often researchers too quickly map a very small set of conventional linguistic metaphors onto a larger conceptual mapping and then draw conclusions about human thought. Semino et al. (2004) show how an individual concept can have a range of conventional literal and metaphorical associates and researchers should carefully evaluate the range before jumping from a linguistic metaphor into a conceptual correspondence. A corpusbased approach supported by Wmatrix can considerably assist the researcher in this process. Insights from a larger amount of linguistic data comprised under a semantic category can reveal a range of linguistic expressions as well as frequent and hence dominant patterns of literal and metaphorical associations that it has in a given context. This, in turn, help make an evidence-based decision. In this research, conceptual mappings were proposed based on corpus evidence, specifically the frequency of the linguistic metaphors (cf. Semino et al. 2004).

\subsection{Data and Procedures}

This paper is based on the analysis of three corpora that include descriptions of tourist destinations in Britain (Home-Corpus), Europe (Europe-Corpus) and in faraway tropical countries (Faraway-Corpus). Table 1 shows the number of tokens in each corpus. The data for the Home-Corpus was sourced from the most popular tourist websites as identified by Google searches. The search term used was the string holiday in the UK. As it turned out, the most popular websites specialised in cottage or farmhouse holidays. Only descriptions of destinations were included in the corpus. Details regarding types of accommodation and travel routes were excluded. The Europe-Corpus and Faraway-Corpus were compiled using 
descriptions of destinations produced by the largest tourism corporations operating in Britain including Thomson Holidays (part of TUI - the world's largest tourism company), Virgin Holidays, Thomas Cook, Sandals and Kuoni Travel. The texts were sourced manually from the companies' websites and describe destinations in Europe (Europe-Corpus) and in developing countries located in Asia and the Pacific region (Faraway-Corpus). Appendix I lists all the destinations included in the data.

Table 1: Size of Corpora

\begin{tabular}{l|r} 
Corpus & Tokens \\
\hline Home-Corpus & 82,863 \\
Europe-Corpus & 82,520 \\
Faraway-Corpus & 82,230
\end{tabular}

Admittedly, the perspective taken in this study is one-sided, as it considers Britain - a Western affluent country - as the starting point and British tourists traveling to tropical destinations located mostly in the East as readers of such descriptions. Having said that, tourism as a global industry is still largely one-directional marked with inequalities. It is mostly the 'first' world people including the British who can afford to travel and together with Americans, Australians and Northern-European populations belong to the group of the world's most well-travelled people. ${ }^{1}$ Thus, the studied case can be seen, in some ways, as a prototypical of the tourism industry nowadays and the British as an example of a target customer. This leads to another point which ought to be mentioned at the outset of this study namely that the notion of 'distance' cannot be purely understood in terms of a length between the point of departure and destination measured in miles or kilometres. Distance is here

\footnotetext{
${ }^{1}$ See the research data published by Timetric at: https://timetric.com/info/media-center/pressreleases/2014/10/09/timetric-reveals-which-countries-travel-most/
} 
meant in cultural and geo-political terms and rather as a degree of cultural familiarity and/or similarity. For example, for an American tourist geographically Western Europe is further away than tropical Grenada, but Western Europe can be generally regarded 'closer' culturally, politically and economically.

Similar to Demmen et al. (2015), firstly a list of metaphorical expressions was created based on close readings of approximately $10 \%$ of the data. The sample included between five and seven randomly selected descriptions of different places from each corpus (approximately 8,000 tokens). Metaphorical expressions were identified using the MIP guidelines (Pragglejaz Group 2007). Accordingly, each text from the sample was divided into linguistic units with proper names and phrasal verbs marked as single segments. Appendix 2 illustrates examples of segmented extracts from the three corpora and gives a flavour of the data under investigation. Metaphorical meanings were assigned based on the comparison between the contextual meaning of the item (the actual word form) and its basic meaning(s) as defined in the full electronic version of the Oxford English Dictionary (OED) (2016). If necessary, the etymology entry was also checked. For example, the item 'home' can be associated with human agents, but in the OED is primarily defined as 'the place where a person or animal dwells' and hence in 'the Elan Valley is home to some of Britain's rarest wildlife', 'home' was not assigned a metaphorical meaning. On the contrary, retreat was identified as a metaphor, because the prime meaning implies an escape from dangerous or difficult situations and danger or difficulty were not implied in the contextual meaning. Arguably, metaphoricity is a matter of degree and the decision to classify a token or phrase as metaphorical is never easy. However, it was thought that considering the basic definition of 
the actual word form (if present) ${ }^{2}$ in the OED was a robust basis to consistently distinguish between the literal and non-literal senses in the studied context.

Although the texts were segmented into single lexical units, in the majority of cases metaphorical expressions emerged across longer chains of units, which often combined different metaphors or metaphors with hyperboles, alliterations and personifications (see Appendix 2). For example, in the phrase 'gloriously gold sand', two items 'gold' and 'gloriously' were identified as being non-literal with alliterated 'gloriously' intensifying the metaphorical meaning of 'gold sand'. The same applies to 'awash', which according to the OED means to be covered with water. In the context under study, 'awash' was used in combination with 'colour' or 'beauty' to refer to places and such phrases were deemed metaphorical because the contextual meaning did not imply water.

Subsequently, all metaphorical expressions that were identified in the sample were manually tagged for source domains corresponding to their literal meaning(s) (cf. Demmen et al. 2015). Table 2 gives an overview of twelve source domains identified in the sample with examples of metaphorical expressions.

Table 2: Major source domains with examples of items used metaphorically

\begin{tabular}{|l|l|}
\hline Source Domain & Examples \\
\hline BODY & heart, heart-warming, sleepy, toe \\
\hline COLOUR & golden, snow-white, green \\
\hline DRUGS & doses, intoxicate \\
\hline PROTECTION & wrapped in, cocoon, blanket \\
\hline PHYSICAL MOVEMENT & retreat, gateway, drift away, entwine \\
\hline
\end{tabular}

\footnotetext{
${ }^{2}$ In most cases the actual word form as used in the corpora, e.g. buzzing, blessed was checked; in instances in which the definition did not elaborate on the prime meaning(s), the closet part of speech was looked up.
} 


\begin{tabular}{|l|l|}
\hline HIGH TEMPERATURE & blazing, warmth, ablaze \\
\hline NATURAL ELEMENT & gold, gem, emerald, crystal \\
\hline RELIGION & paradise, blessed, heaven, soul \\
\hline SOUND & buzzing, sizzling \\
\hline TASTE & taste, deliciously, sweet \\
\hline TOUCH & touch, caressed \\
\hline WRITING & punctuated, dotted \\
\hline
\end{tabular}

In order to identify all possible linguistic metaphors belonging to each of the source domains, all three corpora were uploaded onto Wmatrix and searched using the USAS tags corresponding to the identified domains. To find the equivalent USAS semantic category, items identified as metaphorical were checked for their USAS tags in Wmatrix first. For example, sleepy, toe and heart were all assigned B1, which stands for the USAS semantic category 'anatomy and physiology', whereas gold, gem and emerald were all tagged with O1.1. which represents 'substances and materials: solid'. In most cases, a corresponding USAS category was easily identified. Table 3 shows the source domains with their corresponding USAS domains. However, there were also some source domains whose items spread across different USAS categories. For example, items from DRUGS were located under 'quantities', 'drinks and alcohol' and 'medicines and medical treatment'. In such cases, all USAS categories were searched for items whose primary meanings derive from drugs and medicines (see Table 4).

Table 3: Examples of corresponding USAS domains

\begin{tabular}{|l|l|l|}
\hline Source Domain (Sample) & USAS Tag & USAS Domain \\
\hline BODY & B1 & anatomy and physiology \\
\hline
\end{tabular}




\begin{tabular}{|l|l|l|}
\hline COLOUR & O4.3 & colour and colour patterns \\
\hline DRUGS & B3 & medicines and medical treatment \\
& F2 & $\begin{array}{l}\text { quantities } \\
\text { drinks and alcohol }\end{array}$ \\
\hline PROTECTION & A1.1.1 & general actions/ making \\
\hline PHYSICAL MOVEMENT & A1.7+ & constrain \\
\hline HIGH TEMPERATURE & M1 & moving, coming and going \\
\hline NATURAL PRECIOUS ELEMENT & O1.1 & substances and materials: solid \\
\hline RELIGION & S4.6+ & religion and the supernatural \\
\hline SOUND & X3.2 & sensory: sound \\
\hline TASTE & X3.1 & sensory: taste \\
\hline TOUCH & X3.3 & sensory: touch \\
\hline WRITING & language, speech and grammar \\
\hline
\end{tabular}

Subsequently, items belonging to each USAS domain and their concordance lines were exported to an Excel spreadsheet and carefully scrutinised to identify metaphorical uses by constantly cross-checking the contextual meanings with the OED entries. This was a manual and time-consuming process. For example, 260 items (types) and 1027 concordance lines were retrieved from the semantic domain tagged with M1 from the Faraway-Corpus. Also some metaphors that were identified in the sample were assigned to a different semantic category than the source domain. For example, exude and ooze were originally allocated to the source domain of BODY because of the basic meanings as defined in the OEC with ooze meaning 'to emit liquid or moisture slowly through the pores of a body' and exude 'oozing mostly sweat'. In Wmatrix, both items appeared under 'general actions/ making'. Hence, the 
frequencies of all metaphors identified $a$ priori were checked separately and left in the domain to which they were assigned initially. Despite the lengthy process, the analysis made it possible to capture the diversity and relevance of linguistic metaphors from the source domains identified a priori. It also helped reveal the persistence of additional conceptual mappings that were not immediately obvious to the naked-eye perusal.

\section{Results}

This section summarises the main results of the analysis and provides examples of linguistic metaphors and conceptual mappings identified. Following the procedures described in Section 3.2, a total of 711 metaphorical expressions were retrieved from the twelve source domains, of which 403 were present in the Faraway-Corpus, 251 in the Europe-Corpus and 57 in the Home-Corpus. Table 3 shows the number of items (tokens) that were identified as metaphorical in each source domain. Not only has the Faraway-Corpus a higher density of metaphors (as measured by the frequency of tokens), there is also a greater diversity of metaphorical expressions as shown by the number of unique types in Table 5. In total, 76 different types were identified in the Faraway-Corpus, 60 in the Europe-Corpus and only 13 in the Home-Corpus.

Table 4: Metaphor tokens in the identified source domains

\begin{tabular}{|l|c|c|c|c|}
\hline Source Domain & Home & Europe & Faraway & Total \\
\hline RELIGION & 3 & 42 & 98 & 143 \\
\hline NATURAL PRECIOUS ELEMENT & 1 & 43 & 81 & 125 \\
\hline BODY & 25 & 41 & 53 & 119 \\
\hline PHYSICAL MOVEMENT & 21 & 28 & 32 & 81 \\
\hline COLOUR & 3 & 16 & 41 & 60 \\
\hline
\end{tabular}




\begin{tabular}{|l|c|c|c|c|}
\hline TASTE & 2 & 16 & 27 & 45 \\
\hline WRITING & 0 & 20 & 15 & 35 \\
\hline DRUGS & 0 & 9 & 15 & 24 \\
\hline SOUND & 0 & 9 & 13 & 22 \\
\hline PROTECTION & 0 & 10 & 11 & 21 \\
\hline HIGH TEMPERATURE & 0 & 9 & 10 & 19 \\
\hline TOUCH & 2 & 8 & 7 & 17 \\
\hline Total & 57 & 251 & 403 & $\mathbf{7 1 1}$ \\
\hline
\end{tabular}

Table 5: Metaphor types in the identified source domains ${ }^{3}$

\begin{tabular}{|l|c|c|c|c|}
\hline Source Domain & Home & Europe & Faraway & Total unique \\
& & & & types \\
& & & & 18 \\
\hline NATURAL PRECIOUS ELEMENT & 1 & 9 & 13 & 17 \\
\hline BODY & 1 & 7 & 7 & 11 \\
\hline COLOUR & 3 & 7 & 8 & 9 \\
\hline TASTE & 2 & 5 & 5 & 7 \\
\hline RELIGION & 3 & 6 & 6 & 4 \\
\hline MOVEMENT & 0 & 5 & 5 & 3 \\
\hline HIGH TEMPERTURE & 0 & 4 & 5 & 3 \\
\hline DRUGS & 0 & 4 & 4 & 3 \\
\hline SOUND & 0 & 3 & & 3 \\
\hline PROTECTION & & & & \\
\hline
\end{tabular}

\footnotetext{
${ }^{3}$ Here different forms of a lemma, for example, intoxicate, intoxicates and intoxicating were counted as one type, but sweet and sweetness as two separate types.

${ }^{4}$ The total numbers in this column refer to the number of unique types identified across the three corpora; a sum of the types identified in each corpus would inflate the results, as some types (e.g. heart) would be counted three times or twice.
} 


\begin{tabular}{|l|c|c|c|c|}
\hline TOUCH & 1 & 2 & 2 & 2 \\
\hline WRITING & 0 & 2 & 3 & 2 \\
\hline Total & 13 & 60 & 76 & $\mathbf{8 2}$ \\
\hline
\end{tabular}

The difference in the use of metaphors between Home and Europe-Corpus is highly significant $(\mathrm{LL}=133.71, \mathrm{df}=2, \mathrm{p}<0.0001)$; the $\mathrm{LL}$ value is even greater for the difference between Home and Faraway-Corpus $(\mathrm{L}=295.68, \mathrm{df}=2, \mathrm{p}<0.0001)$ pointing to an extremely significant result. The difference between the Europe and Faraway-Corpus is also highly significant $(\mathrm{LL}=35.66, \mathrm{df}=2, \mathrm{p}<0.0001)$. This means that the use of metaphors from these twelve domains is not due to chance, but a significant feature of texts that are included in the Europe and especially the Faraway-Corpus. The results provide empirical evidence for a greater use of metaphors in descriptions of exotic destinations further away from home and thus confirm the observation suggested by Dann (1996). The following sections offer qualitative insights into the major source domains that have the greatest diversity of metaphorical expressions as indicated by types (Table 5). These are: BODY, NATURAL PRECIOUS ELEMENT, COLOUR, TASTE and RELIGION.

\subsection{Metaphors from the source domain of BODY}

The source domain BODY has the greatest number of unique types (19) and a large number of metaphorical expressions (120). Table 7 lists all types retrieved from each corpus with their frequencies in brackets. Overall, two groups of metaphors within this source domain could be identified. On the one hand, there is a number of items that denote specific Table 7: Metaphors from the source domain BODY

\begin{tabular}{|l|l|}
\hline Home-Corpus & heart (25) \\
\hline Europe-Corpus & heart (13), sleepy (12), ooze (7), foot (5), breath (2), dosy (1), \\
\hline
\end{tabular}




\begin{tabular}{|l|l|}
\hline Faraway-Corpus & finger (1) \\
sleepy (22), heart (18), ooze (3), body (1), exude (1) freckled \\
$(1)$, frisson (1), heart-warming (1), mouth (1), nudged (1), \\
pulse (1), teardrop (1), toe (1)
\end{tabular}

parts of the body such as heart, foot, mouth, finger and toe with heart being the only metaphor used across the three corpora. In most instances, the metaphorical use of such items is highly conventionalised. For example, heart is a conventional metaphor used as an alternative expression of 'middle' or 'central part' as in 'the heart of Cornwall'. The very frequent use of heart indicating centrality suggests a conceptual mapping A TOURIST DESTINATION is A CENTRAL PLACE. This, in turn, highlights the importance of a place making it possibly more attractive to potential tourists.

Similarly, foot ('at the foot of the mountain') or mouth ('at the mouth of the stunning Sal River') are also used conventionally to refer to geographical positions or entities with mouth describing openings and foot denoting lower parts. But the frequency of these items is much lower. On the other hand, we find here a number of metaphors that denote physical or emotional changes in the body and are less conventionalised. Such metaphors are only used in the Europe- and Faraway-Corpus. A frequently employed example is sleepy, which, as Extracts 5-7 show, is used to describe rural tranquil places (mostly villages) implying that they have not been touched by modernity and are places to relax.

5. And if you go inland, you'll find sleepy villages, hidden hamlets and the scenic Troodos Mountains. (Europe)

6. Neighbouring Cha Am is a sleepy fishing village with lovely beaches. (Faraway)

7. Lamai is a shade quieter than Chaweng, whilst Fishermans Village in Bo Phut is seductively sleepy and charmingly laidback. (Faraway) 
Since the metaphor sleepy is the second most frequently used item from the source domain BODY, the link between a place and sleepiness seems quite persistent evoking a mapping A TOURIST DESTINATION IS A SLEEPY BODY.

\subsection{Metaphors from the source domain of NATURAL PRECIOUS ELEMENT}

Table 6 lists all metaphorical types that were identified in this source domain with their frequencies. Most of the items refer to valuable stones and minerals with emerald, gold and the generic gem being especially frequently used. Apart from platinum, which is used in

Table 6: Metaphors from the source domain NATURAL PRECIOUS ELEMENT

\begin{tabular}{|c|c|}
\hline Home-Corpus & emerald (1) \\
\hline Europe-Corpus & $\begin{array}{l}\text { gem (10), turquoise (9), emerald (7), gold (5), crystal (4), } \\
\text { platinum (3), sapphire (3), gemstone (1), silver (1) }\end{array}$ \\
\hline Faraway-Corpus & $\begin{array}{l}\text { turquoise (30), emerald (15), gold (8), platinum (6), gem (7), } \\
\text { crystal (5), ivory (2), amber (1), pearl (1), bronze (1), } \\
\text { alabaster }(1), \text { silica }(1), \text { jade }(1), \text { topaz }(1), \text { pearly }(1)\end{array}$ \\
\hline
\end{tabular}

references to a higher value of goods as in: 'platinum holiday' or 'the 4 star platinum hotel', most of the items describe, in metaphorical terms, attributes of natural entities such as sea water, sands and flora (see Extracts 1-4).

1. Half way along the golden coast, where the sand meets the sea in a sparkling display of gold and sapphire ..... (Europe)

2. The island is a feast for the eyes and soul, with its emerald greenery tumbling down to a coastline honeycombed with pebble bays (Europe) 
3. The ivory sands here come with a supporting line-up of luxury hotels, restaurants and watersports. (Faraway)

4. Pearly white sands, clear topaz seas and emerald palms bowing in the breeze ... (Faraway)

Such uses endow the essentially natural and not particularly spectacular elements of landscape with preciousness and rare beauty. In doing so, they 'lift' them metaphorically to the level of luxury. As the extracts above also show, metaphorical uses of precious stones and metals are often extended with other metaphors from the domain of COLOUR and MOVEMENT (cf. Phillips 2011). This intensifies the sense of luxury or add dynamism. Since all the items belong to precious natural elements of high value used mostly to produce expensive and desirable jewellery, their use in descriptions of landscapes creates inescapably an image that can be captured by the mapping ELEMENTS OF LANDSCAPE ARE JEWELS.

\subsection{Metaphors from the source domain of COLOUR}

A number of creative uses of metaphors could be identified when examining items from the source domain of COLOUR. Alongside prototypical references, colour words have a range of attributive and connotative meanings that are often exploited for metaphorical purposes and other special effects (Philip 2006). These are often realised in extensions combining colour terms with pre- or post-modifiers that intensify metaphorical meanings (Philip 2011: 175). In total 58 instances of metaphorical uses of colour terms were identified in the three data sets with most instances occurring in the Europe- and Faraway-Corpus, 18 and 37 times respectively (see Table 8 ).

Table 8: Metaphors from the source domain COLOUR

\begin{tabular}{|l|l|}
\hline Home-Corpus & golden (1), green (1), colour (1) \\
\hline
\end{tabular} 


\begin{tabular}{|l|l|}
\hline Europe-Corpus & $\begin{array}{l}\text { green (3), white (5), honey-coloured (3), golden (2), blue (1), } \\
\text { mellow (1), pastels }(1)\end{array}$ \\
\hline Faraway-Corpus & $\begin{array}{l}\text { golden (19), white (10), blue (6), faded (2), green (2), burnt- } \\
\text { orange (1), scarlet (1) }\end{array}$ \\
\hline
\end{tabular}

As Table 8 shows, the most productive colour terms appear to be golden (22 metaphorical occurrences in total) followed by white (15), green (8) and blue (7). 'Golden' is an adjective derived from the noun 'gold', which is the most precious metal used to produce jewellery. It is a preferred metal for wedding rings, because it symbolises happiness which should never diminish with time (Stewart 1998). Items that are golden are thus considered precious, luxurious and also permanent. As Extracts $8-9$ below demonstrate, golden is mostly used to describe beaches and sands attributing them with luxury and thus intensifies the metaphorical mapping identified above that ELEMENTS OF LANDSCAPE ARE JEWELS.

8. Stretch out on a velvety blanket of golden sand. (Europe)

9. As you explore you will find golden sunkissed beaches, warm and friendly people and acres of coastal forest. (Faraway)

Symbolism associated with white includes purity, innocence and cleanliness. In the Europe- and specifically Faraway-Corpus, white is used to describe beaches reinforcing the idea of clean and pure spaces. It is important to note that the metaphoricity of the colour terms derives, in most instances, from their neighbouring items, that is, extensions with other attributes, personifications or similes (cf. Philip 2011). For example, beaches are not described just as white but as 'dreamy white' or 'pearly white'. Other metaphorical uses of colour terms with additional attributions include descriptions of see waters as 'calm blue' or 'crystal blue' and green spaces as 'emerald green' or 'silvery green'. In the data under study, 
there were also 2 instances of idiomatic expressions with green as in 'and it's got attractions and nightlife that would make some cities green with envy'.

Perhaps the most interesting pattern that emerged when studying the contexts in which colour descriptors were used metaphorically was the striking occurrence of items from the domain of arts in the vicinity of colour terms, in total 11 times, of which 6 in the Faraway and 5 in the Europe-Corpus. As Extracts $10-13$ show, in the Europe and the Faraway-Corpus some elements of the landscape are clearly portrayed as paintings. This is indicated with nominal and verbal pre-modifiers such as 'brushstrokes of', 'patchwork of', 'a drop of', 'canvas of', 'splashed with' or 'sprinkled with':

10. On top of that, the countryside here is just as breath-taking as the coastline, so dive right in and discover a pretty patchwork of green forests. (Europe)

11. Great brushstrokes of golden sand, backed by gentle dunes and punctuated by gigantic islands of rock. (Europe)

12. You'll find it in the heart of the old city, exploding into life beneath a sky splashed with swirls of scarlet. (Faraway)

13. This place is a colourful canvas of turquoise seas, golden sands with a drop of green in the background. (Faraway)

Such modifiers from the domain of arts seem to point to rather subtle techniques of painting resembling the impressionistic approach to art as opposed to firm lines and contours of the neoclassical style. In doing so, they produce an image of a beautiful landscape to be admired by the reader who has now turned into a viewer. The 'impressionistic style' does not deliver a picture with clearly defined lines, but rather a subtle or slightly blurred image ('splashed with pastels', 'a drop of green') that leaves quite a bit of room for imagination. This is a powerful technique of textual visualisation that appeals to both perception and fantasy taking the 
reader/viewer on an imaginary voyage even before embarking on the actual journey. Such imagery is only employed in descriptions of destinations in Europe and tropical countries thus pointing to the relevance of the conceptual mapping A TOURIST DESTINATION IS A PAINTING in both contexts.

\subsection{Metaphors from the source domain of TASTE}

The domain of TASTE appears to be too a productive source of metaphorical expressions in the descriptions of tourist destinations. In total, 45 tokens and 15 unique types could be identified across the three data sets. As in the previous cases, taste metaphors were mostly present in the Faraway-Corpus followed by the Europe-Corpus. Table 9 shows the types of metaphorical items from this domain with their frequencies.

Table 9: Metaphors from the source domain TASTE

\begin{tabular}{|l|l|}
\hline Home-Corpus & flavour (1), taste (1) \\
\hline Europe-Corpus & taste (8), delicious (5), deliciously (1), sweet (1), sugary (1) \\
\hline Faraway-Corpus & $\begin{array}{l}\text { taste (12), flavour (7), sugary (3), delicious (1), spicy (1) } \\
\text { sweet (1), aromas (1), sweetness (1) }\end{array}$ \\
\hline
\end{tabular}

As can be seen, taste, flavour and delicious were used metaphorically more often than other items identified in this domain. In the case of taste, many examples include a personification, in which a place or a country is attributed with the sense of taste to promote local food. This was the case in the Home- and Europe-Corpus, in which names of countries were used as post-modifiers as in 'the taste of Scotland', 'a taste of authentic Greece'. In the FarawayCorpus, the instances of post-modifiers of taste and flavour were rarely names of countries and not necessarily associated with actual local food. Examples found in this corpus include 
expressions such as 'a true taste of romantic seclusion', 'a flavour of exoticism' or 'taste of paradise'. They seem to capitalise on the sensory experience of taste to describe sensations ('seclusion') or abstract phenomena ('paradise'). Similar uses were identified with the items delicious, deliciously and sugary that were used to describe elements of nature, specifically sands and beaches (see Extracts $14-17$ ).

14. Pad down to the sweep of sugary soft sands and stretch out in style (Europe)

15. Fronted by a long palm-studded promenade, the resort fixes its sights firmly on a delicious crescent-shaped bay. (Europe)

16. We 're talking sugary sands and every kind of watersport down at the idyllic Palm Beach (Faraway)

17. Cuba Cuba holidays offer a delicious cocktail of stunning beaches, Latin rhythms and modern living (Faraway)

Recent research concerned with the use of taste metaphors has shown that sentences with taste metaphors are more emotionally engaging than their literal counterparts (Citron and Goldberg 2014). They spark more activity in the emotion-related parts of the brain and in doing so, intensify the impact of the sentences by eliciting emotional responses. This effect gives taste metaphors a 'rhetorical advantage', which, in turn, seems to facilitate persuasion. Furthermore, when examining the instances of taste metaphors, it also became apparent that they were, at times, used as pre-modifiers of other sensory words as in 'sugary soft sands' and 'deliciously cold_waters'. These are examples of cross-sensory expressions referred to as synesthetic metaphors (Nelson and Hitchon 1999), whereby one sense (e.g. taste) is described by making references to another (e.g. coldness). Cross-sensory metaphors can be powerful persuasive devices; research concerned with the impact of synesthetic metaphors used in adverts has shown that they evoke pleasant sensory experiences and tend to engage the 
consumer more than their literal equivalents (Nelson and Hitchon 1999). All in all, the evidence suggests that descriptions further away from home, but elements of tropical destinations in particular are sometimes described by drawing on taste metaphors. This can be condensed to the conceptual mapping of ELEMENTS OF LANDSCAPE ARE A (SWEET/DELICIOUS) TASTE.

4.5 Metaphors from the source domain of RELIGION

The domain of RELIGION proved very productive producing the largest number of metaphorical expressions (147 in total). Having said that, the number of tokens was lower than in the case of the domains discussed above meaning that religion metaphors were reused very frequently. This applies to paradise and heaven that were the most frequent tokens identified in the data (see Table 10).

Table 10: Metaphors from the source domain RELIGION

\begin{tabular}{|l|l|}
\hline Home-Corpus & heaven (1), blessed (1) \\
\hline Europe-Corpus & $\begin{array}{l}\text { paradise (19), heaven (13), soul (4), blessed (3), worshipping } \\
(2), \text { sun-worship (1) }\end{array}$ \\
\hline Faraway-Corpus & paradise (61), blessed (15), heaven (9), spirit (7), soul (6) \\
\hline
\end{tabular}

Paradise and heaven are synonymous biblical terms used to refer to the abode of God and the place to which only the redeemed or chosen are allowed. Paradise/heaven is the land of plenty, associated with peace, happiness and light. It is contrasted with the underworld of hell, which is the abode of the evil and darkness. This metaphoricity has its roots in the conceptual mapping of GOOD is UP (Lakoff and Johnson 1980), but it would be somewhat simplistic to consider the use of such metaphors to conceptually map tourist destinations as 
just good. It is rather the associations with plenty that contribute to the imagery in this context. As Extracts $18-21$ demonstrate, paradise or heaven are at times preceded or followed by a noun phrase 'buzzing party paradise', 'adventurers' paradise', 'naturalists' heaven',

18. The unmissable Uffizi gallery, the architecture and endless art galleries. A paradise for art lovers! (Europe)

19. The resort 's a buzzing party paradise, bustling with cutting-edge clubs and trendy bars. (Europe)

20. The magical states of Sarawak and Sabah in Malaysian Borneo are an adventurers' paradise, a naturalists' heaven and a beach lovers' dream. (Faraway)

21. The island is not large at just 21 miles long and 14 miles wide but you'll find everything you could wish for in this little patch of paradise. (Faraway)

'paradise for art lovers' offering a specification which narrows down the meaning to a particular interest group such as art lovers or party goers. Paradise and heaven lose here their religious connotations and have a more specific meaning of having something in abundance making a tourist destination attractive for a particular interest group. In fact, 8 of all occurrences of paradise in the Europe-Corpus and 12 in the Faraway-Corpus were preceded or followed by a specific nominal phrase including 'bird watchers', 'beach lovers', 'photographers' and 'golf players'. This could be subsumed under a conceptual metaphor of A TOURIST DESTINATION is A LAND OF PLENTY. All other instances referred to the description of islands, especially tropical islands as in 'Tobago is a tropical paradise with captivating scenery, friendly islanders and picturesque beaches' or 'You'll gain insider insights and a whole new perspective on this beautiful island paradise'. This suggests a conceptual 
mapping of A TROPICAL ISLAND is A PARADISE evoking an image of peace, happiness and beauty.

The deployment of the metaphor of paradise to describe tropical islands seems to be a myth deeply entrenched in the popular imagining going back at least to the $17^{\text {th }}$ century. Tourism researchers argued that it was precisely this myth that made mass tourism the dominant industry in many tropical and previously colonised islands whose natural conditions were less favourable to mass agriculture (e.g. the failed sugar plantations in the Bahamas) (Strachan 2002; Deckard 2010; Nixon 2015). The metaphor of paradise with its associations of pristine landscapes and happiness has become the selling point for islands that were seen as in need of 'development'. As a consequence, mass tourism rapidly increased making the places hugely dependent upon international tourism industry with obvious negative outcomes such as overpopulation, shortage of resources, inequalities etc. Despite initiatives promoting sustainable tourism, many of the places, especially if one ventures outside the purpose-built tourist resorts, are plagued with poverty, pollution, exploitation and health issues conveniently disguised by the metaphor of paradise. In this way, the metaphor can be seen as performing ideological work in that it is a frequent device in the discourse which perpetuates colonisation by other means.

\section{Conclusions}

The results shown above suggest a statistically significant increase of metaphors in the descriptions of popular tourist destinations that are located further away from 'home', specifically tropical destinations. Thus, they provide tangible evidence supporting the claim that the use of metaphorical language increases with a greater cultural distance. Whereas metaphors used in the Home-Corpus are mostly examples of conventional figurative expressions from the domain of BODY, instances of metaphors in the two other corpora draw 
heavily on other domains including RELIGION, NATURAL SUBSTANCE and the sensory experience of COLOUR and TASTE. Drawing on the corpus evidence and frequency of linguistic metaphors in each domain, a number of specific conceptual mappings could be identified including: 1) A TOURIST DESTINATION is A CENTRAL PLACE, 2) A TOURIST DESTINATION IS A SLEEPY BODY, 2) A TOURIST DESTINATION IS A PAINTING, 3) A TOURIST DESTINATION is A LAND OF PLENTY, 4) ELEMENTS OF LANDSCAPE ARE JEWELS, 5) ELEMENTS OF LANDSCAPE ARE A (SWEET/DELICIOUS) TASTE and 6) A TROPICAL ISLAND is A PARADISE. Metaphors from these conceptual mappings work collectively to evoke images of important, unspoilt, luxurious and colourful places of rare beauty and with plenty of resources and attractions - features that are highly desirable by tourists, specifically those travelling to tropical destinations. They appeal simultaneously to imagination, vision and taste creating sensory fusions that could potentially increase the 'appetite' for 'consuming', that is, buying a trip to a tropical destination. At the same time and similar to work by Koller (2009) and Velasco-Sacristán and Fuertes-Olivera (2005), the persuasive use of metaphors here happens on two levels. On the one hand, the metaphors create sensory imageries that play on the imagination. On the other hand, they transmit ideologically laden messages that clandestinely conceal aspects of the reality and in doing so, are instrumental in reinforcing colonial and neo-colonial legacies. They are not as harmless as it might appear at the first glance. As recent work by Nixon 2015 has shown, the myth of paradise has largely contributed to the deepening of gendered and racial inequalities in the developing world and there is a growing intellectual resistance towards it.

A question which immediately arises is why such a powerful sensory imagery is prominent in the descriptions of faraway destinations and absent in the promotion of places at 'home'? One explanation could be the fact that faraway destinations are likely to be less familiar to the reader. After all, holidays in Asia and the Pacific region are very expensive 
and only affordable by a minority of people. The tourist industry might exploit this lack of familiarity by offering imaginary visions of a dream holiday to create a desire and attract more customers. Also, the powerful imaginary associated with the deeply entrenched metaphor of paradise in combination with the jewel and colour metaphors conveniently erases serious ecological and social problems that affect destinations making them more appealing. In contrast, destinations at home are possibly familiar to a larger number of people. Offering metaphorical sensual visions might possibly generate a degree of suspicion because this is not what is normally expected in the context of a holiday in the UK.

Using the combination of a qualitative analysis with a quantitative corpus-assisted methodology supported by Wmatrix proved useful in identifying types (diversity) and tokens (density) of linguistic metaphors in each source domain. It also helped reveal conceptual mappings that were not immediately obvious when studying a smaller sample of the data qualitatively. The procedures adopted in this study provide framework that can easily be replicated to study metaphors in the same or other discourse domains. Having said that, a substantial part of this research was based on a manual analysis, which involved examination of many lines of concordances and constant cross-checking with the OED entries. This was a time-consuming process, which could be difficult to adopt to study very large corpora.

Furthermore, the types of holidays included in each corpus varied and not only in terms of location, but also price and activities. Whereas the destinations in Britain were mostly lowerbudget cottage holidays, those marketed in Europe and especially in tropical destinations included more expensive hotel-based packages. It can be assumed that the 'price' factor and associated luxury may play a role in the representations of tourist destinations in that the more expensive holidays might be marketed by utilising more metaphors than descriptions of cheaper packages. Future research could test the significance of the price factor by examining descriptions of luxury holidays, for example spa holidays based in the UK to see whether 
they too rely on metaphors to the same extent as descriptions of holidays in faraway tropical destinations. Given the prominence of visual information in tourism promotion and marketing, future research would also need to focus on the use of metaphors in images. Finally, the effects of the metaphors identified in this research on readers of these types of texts would need to be established empirically using more experimental techniques.

\section{References}

Abuczki, A. (2009). The use of metaphors in advertising. A case study and critical discourse analysis of advertisements in Cosmopolitan. Argumentum, 5, 18-24.

Ang, S. H \& Lim, E. (2006). The influence of metaphors and product type on brand personality perceptions and attitudes. Journal of Advertising, 35(2), 39-53.

Bauman, Z. (1993). Postmodern Ethics. Cambridge/MA: Basil Blackwell.

Bigné, J. E., Sánchez, M. I. \& Sánchez, J. (2001). Tourism image, evaluation variables and after purchase behaviour: inter-relationship. Tourism Management, 22(6), 607-616.

Bhatia, V. (2005). Generic patterns in promotional discourse. In H. Halmari and T. Virtanen (eds.), Persuasion Across Genres: A linguistic Approach (pp. 213-225). Amsterdam: John Benjamins

Breeze, R. (2013). Corporate Discourse. London: Bloomsbury.

Burgers, C., Konijn, E., Steen, G. \& Iepsma, M. (2015). Making ads less complex, yet more creative and persuasive: the effects of conventional metaphors and irony in print advertising. International Journal of Advertising, 34(3), 515-532.

Caballero (2009). Cutting across the senses: Imagery in winespeak and audiovisual promotion. In Ch. Forceville and E. Urios-Aparisi (eds.), Multimodal Metaphor (pp. 7394). Berlin: de Gruyter. 
Charteris-Black, J. (2004). Corpus Approaches to Critical Metaphor Analysis. Basingstoke, UK: Palgrave.

Chen, Ch. \& Tsai, D. (2007). How destination image and evaluative factors affect behavioral intentions? Tourism Management, 28(4), 1115-1122.

Citron, F. M. \& Goldberg, A. (2014). Metaphorical sentences are more emotionally engaging than their literal counterparts. Journal of Cognitive Neuroscience, 26(11), 2585-2595.

Dann, G. (1996). The Language of Tourism: A Sociolinguistic Perspective. Wallingford: CAB International.

Deckard, S. (2010). Paradise discourse, imperialism, and globalisation: exploiting Eden. New York and London: Routledge.

Deignan, A. (2005). Metaphor and Corpus Linguistics. Amsterdam, Netherlands: John Benjamins.

Demmen, J., Semino, E., Demjen, Z., Koller, V., Hardie, A., Rayson, P. \& Payne, S. (2015). A computer-assisted study of the use of violence metaphors for cancer and end of life by patients, family carers and health professionals. International Journal of Corpus Linguistics, 20(2), 205-231.

Djafarova, E. and Andersen, H. (2008). The contribution of figurative devices to representation of tourism images. Journal of Vacation Marketing, 4(4), 291-303. Erjavec, K. (2004). Beyond Advertising and Journalism: Hybrid Promotional News Discourse. Discourse \& Society, 15(5), 553-578.

Gibbs, R. W. (2010). The wonderful, chaotic, creative, heroic, challenging world of researching and applying metaphor: A celebration of the past and some peeks into the future. In Low, G., Todd, Z., Deignan, A. \& Cameron, L (eds.), Researching and applying metaphor in the real world (pp. 1-18). Amsterdam and Philadelphia, PA: John Benjamins. 
Koller, V. (2006). Of critical importance: Using corpora to study metaphor in business media discourse. In A. Stefanowitsch \& S. Th. Gries (eds.), Corpus-based Approaches to Metaphor and Metonymy (pp. 229-257). Berlin: Mouton de Gruyter.

Koller, V. (2009). Brand images: multimodal metaphor in corporate branding messages. In Ch. Forceville \& E. Urios-Aparisi (eds.), Multimodal Metaphor (pp. 45-71). Berlin: de Gruyter.

Koller, V., Hardie, A., Rayson, P. \& Semino, E. (2008). Using a semantic annotation tool for the analysis of metaphor in discourse. Metaphorik.de, 15. Retrieved from http://www.metaphorik.de/de/journal/15/using-semantic-annotation-tool-analysismetaphor-discourse.html (last accessed January 2016).

Lakoff, G. \& Johnson, M. (1980). Metaphors We Live By. Chicago, IL: University of Chicago Press.

Mattiello, E. (2012). Metaphor in tourism discourse: Imagined worlds in English tourist texts on the web. Textus, 1(1), 67-82.

McQuarrie, E. \& Mick, D. (1999). Visual rhetoric in advertising: Text-interpretive, experimental, and reader-response analyses. Journal of Consumer Research, 26, 37-54.

Musolff, A. (2004). Metaphor and Political Discourse. Analogical Reasoning in Debates about Europe. Basingstoke: Palgrave-Macmillan.

Nelson, M. \& Hitchon, J. (1999). Loud tastes, colored fragrances, and scented sounds: how and when to mix the senses in persuasive communications. Journalism \& Mass Communication Quarterly, 76, 354-372.

Nixon, A. (2015). Resisting Paradise. Tourism, Diaspora, and Sexuality in Caribbean Culture. University Press of Mississippi.

Partington, A. (2006). Metaphors, motifs and similes across discourse types: Corpus-Assisted Discourse Studies (CADS) at work. In A. Stefanowitsch \& S. Th. Gries (eds.), Corpus- 
based Approaches to Metaphor and Metonymy (pp. 267-304). Berlin: de Gruyter: 267304.

Philip, G. (2006). Connotative meaning in English and Italian colour-word metaphors. In: metaphorik.de, 10. Retrieved from:

http://www.metaphorik.de/sites/www.metaphorik.de/files/journalpdf/10_2006_philip.pdf (last accessed January 2016).

Philip, G. (2011). Colouring meaning: collocation and connotation in figurative language. Amsterdam: John Benjamins.

Phillips, B. \& McQuarrie, E. (2009). Impact of advertising metaphor on consumer beliefs: Delineating the contribution of comparison versus deviation Factors. Journal of Advertising, 38(1), 49-61.

Pragglejaz Group. (2007). MIP: A method for identifying metaphorically used words in discourse. Metaphor and Symbol, 22(1), 1-39.

Rayson, P. (2008). From key words to key semantic domains. International Journal of Corpus Linguistics, 13(4), 519-549.

Semino, E., Heywood, J. \& Short, M. (2004). Methodological problems in the analysis of metaphors in a corpus of conversations about cancer. Journal of Pragmatics, 36, 12711294.

Strachan, I. (2002). Paradise and Plantation: Tourism and Culture in the Anglophone Caribbean. Charlottesville: University of Virginia Press.

Thibodeau, P. H. \& Boroditsky, L. (2011). Metaphors we think with: the role of metaphor in reasoning. PLoS ONE, 6(2), 1-11.

Urry, J. (1990). The Tourist Gaze. London: Sage. 
Velasco-Sacristán, M. \& Fuertes-Olivera, P. (2005). Towards a critical cognitive-pragmatic approach to gender metaphors in Advertising English. Journal of Pragmatics, 38, 19822002.

World Tourism Organisation (UNWTO). 2014. Tourism Highlights, 2014 Edition. http://mkt.unwto.org/publication/unwto-tourism-highlights-2014-edition [last accessed January 2016].

Appendix 1:

Descriptions of destinations in the following countries were included in the corpora

\begin{tabular}{|l|l|}
\hline Home-Corpus & England, Scotland, Wales, \\
\hline Europe-Corpus & Cyprus, France, Greece, Italy, Portugal, Spain \\
\hline Faraway-Corpus & $\begin{array}{l}\text { India, Indonesia, Caribbean Islands, Malaysia, Maldives, } \\
\text { Mauritius, Nepal, Sri Lanka, Thailand, Vietnam }\end{array}$ \\
\hline
\end{tabular}

Appendix 2:

Appendix 2: Extracts from the pilot sample analysed using the MIP guidelines (Pragglajez Group 2007)

Items (phrases o single tokens) in italics were identified as metaphorical

\section{Home-Corpus}

Rhayader|: Ideal| for| all| country| activities| in| the | heart| of | Mid Wales| with| attractive| market| towns| and| the| spectacular| Elan Valley|, Radnor Forest| and| Offa's Dyke|. A| historic| market| town| on| the| banks| of| the| River Wye|, some| 20| miles| from| its| source| on| the| Plynlimon| range| of| the| Cambrian Mountains|; population| 2,000|. The| mountain| road| to| Cwmystwyth| and| Devil's Bridge| has| been| described| as| one| of| the| most| scenic| drives| in| the | world|. The| town| is| the| gateway| to| a| spectacular| complex| of| reservoirs| and dams| in| the| Elan Valley| and | is| home| to| some| of| Britain's| rarest| wildlife| and| plants|. 


\section{Europe-Corpus}

Holidays| in| Alte| involve| strolling| through| the| citrus| groves|, tucking into| heart-warming | local| cuisine | and| enjoying| large| doses| of taking| it| easy|. For| this| is| a| rural| retreat| where| nightlife| consists| of| a| chilled| bottle| of| vino verde| and| a| rustic| meal| under| the| stars|. Often| judged| to| be| one| of| the| prettiest| villages| in| the| Algarve|, it's| all| whitewashed|, cobbled| lanes| and| impossibly| elaborate| chimneys|.

Explore| the| many| walking| trails| which| criss-cross| the| citrus| scented| hills|. Take| a| dip| in| the| deliciously| cool| River Alte!| Picnic| in| the| shade| of| an| almond| tree|. If| you| can't| resist| the| lure| of| the| coast|, jump| in| the| car| to| discover| the| swathes| of| sand| and| craggy| cliffs| further| south|.

\section{Faraway Corpus}

Falling| like| a| teardrop | from| the| Indian| subcontinent| into| translucent|, glass-like| waters|, this| lush| paradise | has| an| abundance| of| attractions| to| entice| its| visitors... snow-white| beaches | glisten| in| the| midday| sun|, mysterious| ancient| cities| lay| forgotten|, traditional| dances $\mid$ intoxicate| the | senses| and |locals| exude| a| genuine|, hospitable| warmth|.

Sri Lanka| is | awash| with| colour|, vibrancy| and | beauty| from| the| swathes| of | gloriously| gold| sand| to| the| verdant|jungles| entwined| around| ancient| monuments| beneath| blazing| blue| skies|. This| little| country| at | the | toe $\mid$ of $\mid$ India $\mid$ is| a| brilliant| gem|, wrapped in $\mid$ gold $\mid$ and| lapped| by| the| cerulean| Indian Ocean|. 